\title{
Cartas Celestes XIV \\ (Celestial Maps XIV) \\ by Almeida Prado
}

\section{Carmen Celia Fregoneze}

(EMBAP)

ABSTRACT: This paper discusses the work for piano "Cartas Celestes XIV", by Almeida Prado. The aim of this study is to analyse the musical and technical demands of the piece as a means to help the piano performance.

KEYWORDS: Almeida Prado; Cartas Celestes; Brazilian Music 
One of the most prolific composers in Brazil, Almeida Prado (1943 2010) became well-known after he won the Composition Contest of Guanabara Rio de Janeiro in 1969. The competition enabled him to leave the country to study with Nadia Boulanger and Olivier Messiaen in Paris (1969-1973). Prado is a religious and mystical person, and following the model of Messiaen, Prado's music has a spiritual appeal and a singular style. The subject of his works often relates to matters of mysticism, ecology, astrology, and/or Afro-Brazilian themes. He began as a cultivator of nationalism (1960-1965) but was compelled to look for another means of self-expression. Prado stated that he set out "to have reached a high level of aesthetic freedom, not being attached to any style, mixing different techniques and aesthetics as it is convenient to him (Mannis, 2005, p.41)."1 Indeed, his output encompasses a wide variety of tendencies: atonalism, postserialism, extended and free-tonalism.

Almeida Prado wrote fourteen Cartas Celestes, a set of works depicting the Brazilian sky and the constellations, commissioned by the Planetarium of the Ibirapuera Park in Sao Paulo (June 1974). These pieces demonstrate the originality of the composer's language and are one of the greatest achievements in the Brazilian piano repertoire of the last two centuries. In Cartas Celestes the composer adopted a harmonic language called transtonality, defined by himself as "the use of tonal elements, but without concerns with the tonal structure; consequently, tonal chords become as independent as atonal chords" (Prado, 1974, s/p) ${ }^{2}$. The work approached here is the cycle's closing piece: Cartas Celestes XIV for piano. New Cycle - The sky seen in Brazil in February and March. Based on the book "Atlas Celeste" by Ronaldo de Freitas Mourao ${ }^{3}$, composed for the Bienal Brasileira

\footnotetext{
${ }^{1}$ Almeida Prado afirma ter alcançado um alto grau de liberdade estética, não se prendendo a estilos e misturando diferentes técnicas e estéticas como lhe convém. Jose Augusto Mannis, Centro de Documentação de Música Contemporânea, 41/2005, Unicamp, Brasil.

2 Transtonalismo - utilização de elementos tonais, porem sem a preocupação com a estrutura tonal, o acorde tonal tornando-se então, uma figura sonora tão independente quanto um acorde atonal.

${ }^{3}$ Cartas Celestes XIV piano. Novo ciclo. O céu visto do Brasil nos meses de Fevereiro e Março. Baseado no livro "Atlas Celeste" de Ronaldo Rogerio de Freitas Mourão.
} 
de Musica Contemporanea (2001). This piece was premiered by and dedicated to Benjamin da Cunha Neto, and sponsored by the Bolsa Vitae de Artes 2001, Rio de Janeiro.

On February 21, 2005 Almeida Prado sent a manuscript to the author and in the attached letter he wrote: "The Cartas Celestes XIV, the last, follows the same scheme of the first six, in which the basic material are the 24 chords, which replace the 24 letters of the Greek alphabet in order to designate the Constellations." 4 [sic]

Cartas Celestes XIV is a large-scale work in four movements: Open Clusters IC 2391 (Aglomerado Aberto IC 2391). Constellation of Auriga (Constelação de Auriga), Open Clusters NGC 2925 (Aglomerado Aberto NGC 2925), and Constellation of Carina (Constelação de Carina). In this piece the combination of highly demanding technical difficulties with an extremely sophisticated approach to tone production challenges the pianist's understanding of the sound capabilities of the instrument. According to the composer, his music "aims to work on the resonances and use of pedal, creating colors and new figurations through the overtones." ${ }^{5}$ In fact, the composer expanded the use of the instrument to the extreme, taking the musical elements to another dimension. As in many works of twentieth-century composers, timbre became an independent parameter and is of utmost importance to the musical texture and to matters of piano technique. Therefore, it is necessary to have a distinctive playing technique exploring all possible sound effects and tone color of the piano to convey the character and exuberance of the musical ideas. These innovations and techniques will be discussed as they pertain specifically to each movement.

Through indications of tempo and character notated in the score, the composer establishes the character and emotional content of each movement. Consequently, the interpreter is able to look for means to bring out the wide variety of timbres and overtones, imparting different color to the texture,

\footnotetext{
${ }^{4}$ As Cartas Celestes no.14, a última, segue o mesmo esquema das 6 primeiras, cujo material de base são os 24 acordes que se colocam no lugar das 24 letras do alfabeto grego, para designar as Constelações.

${ }^{5}$ Almeida Prado, O Som de Almeida Prado. Serie Interpretação e Música Brasileira, gravado em Agosto na Sala Cecilia Meireles, 1999.
} 
exploring the dynamics, and experimenting with pedal resonances. Moreover, the accuracy of tone color can be acquired through two resources that have a major role in this piece: touch and articulation. The varied use of accents generates large contrasts in sound, rhythmic displacements, musical tension, emphasis on the melodic lines or important notes within a melody or phrase, as well as reinforcement of the irregular meters. In addition, the use of accents contributes to matters of timbre, timing, dynamics, and rhythmic vigor. (fig. 1)

Figure 1- Measures 6-12

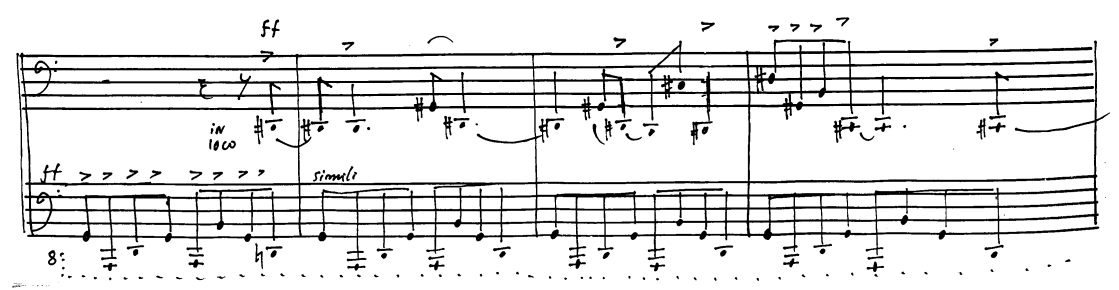

The first movement, Lento, presents an impressionistic atmosphere, with open sixth chords in pianissimo, long use of pedals, and an absence of a strong tonal center. Extremely concise - fifteen measures - the movement contains two distinctive musical phrases, set apart by two chords, both preserving chordal texture. Two-note slurs indicate the inflection of the phrases and establish a musical contrast between them. It requires a delicate approach in terms of sound, control of dynamics, touch, phrasing, and accurate use of pedals.

The second movement (94 measures) is characterized by variety. The harmonic vocabulary is built on nine chords denominated Delta, Alpha, Epsilon, Zeta, Eta, Iota, Beta (2), and Theta. As the composer stated, the chords are the basic material of the piece and generate the cohesiveness of the form. Furthermore, they function as a germinal idea within sections and are restated and varied through the modification of basic elements - melody, rhythm, meter, texture, and timbre. Also, the chords reappear in different registers, covering the entire keyboard, growing and decreasing in intensity, to respond to the matters of timbre. Contrasting sound approaches convey the constant change of moods and character-Intenso, Heróico, and Misterioso. 
To create a logical phrase structure, the composer favors metrical asymmetry. The use of divisive and additive meters - 2/4, 4/4, 5/8, 7/8, 1/4 occur throughout, especially when the main theme is restated in the beginning of different sections. The dramatic end of the phrases in the $1 / 4$ measure causes a recurrent difficulty in the first movement: wide skips from the middle register to the low and high register. The preparation for the jumps requires physical, aural and emotional response, since this is the arrival point of the phrases played in $\mathrm{ff}$ and in short duration. (fig. 2)

Figure 2- Measures 30-32

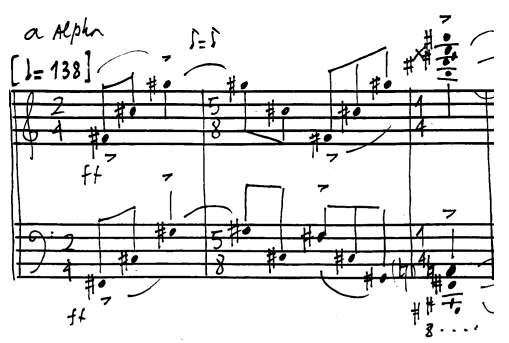

The recurrent use of parallel and contrary motion is the primary organizing melodic device and is the composition's unifying motive. In some letters, for instance Delta, Alpha, Epsilon, and lota, the melodic contour is angular and it is often repeated in a different way - inversions, chordal textures, different registers, distinctive rhythms and intervals - but preserving the same pitches. The melodic design in unison is constructed out of similar contours in different sections, with changes occurring only through the use of new chordal structures and pitches. (figs. 3, 4, 5, 6)

Figures 3, 4, 5 and 6- Measures 1-5/ 30-34/ 55-58/72-75

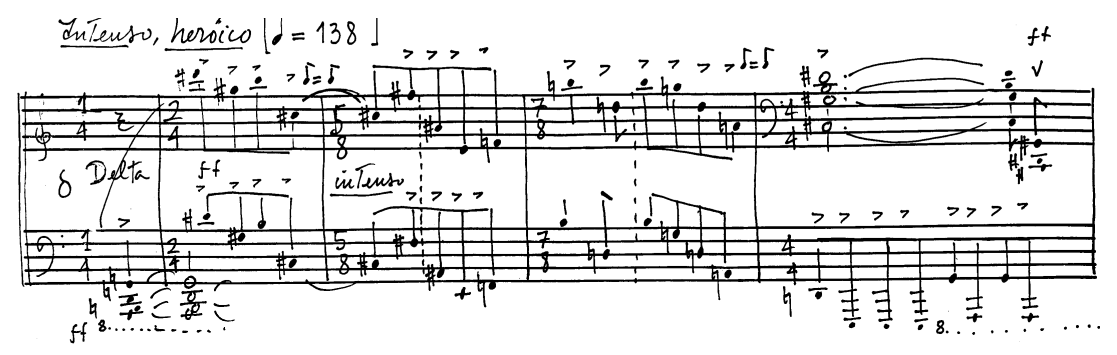



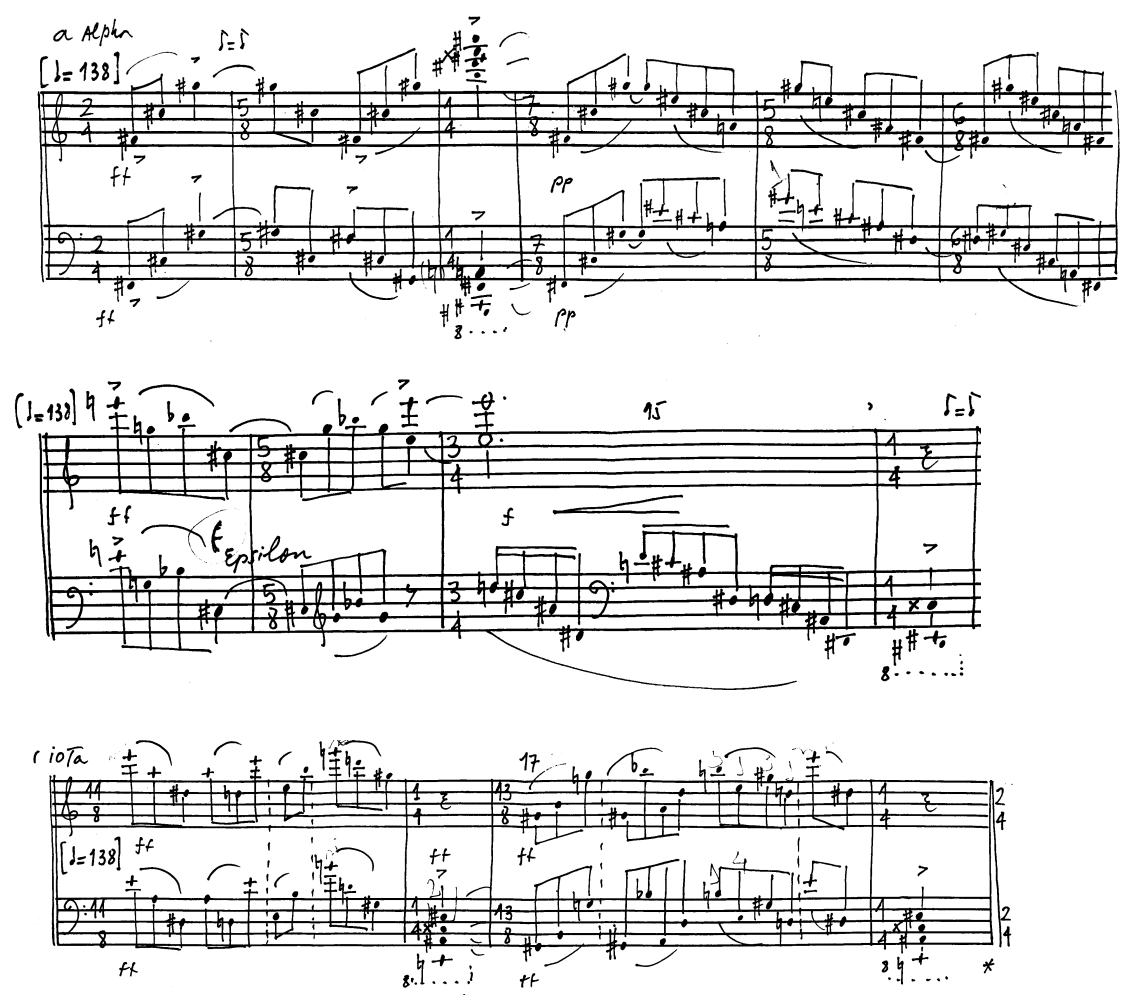

Consequently, the fusion of compositional devices is intrinsically related to the wide range of technical patterns and musical ideas. The technical issues are presented in passages containing irregular rhythms, asymmetrical phrases, angular melodies, hybrid textures, and timbre. To play irregular meters and asymmetrical phrases, physical gestures must be adequate for the different phrase inflections and need to be incorporated until they become natural. In addition, part of the technical difficulties comes from the angularity of the melody, which constantly changes the key center. The nature of the melodic figure is difficult in itself; and although there is a prevailing intervallic structure, the hands have to move in different positions, demanding an adjustment of weak and strong fingers, large finger stretching, as well as coordination of asymmetrical movements of hands and arms.

There is often a virtuosic passage in each letter that functions as a development of the melody, building the climaxes and musical tension of the section. To build such moments, Prado usually takes a pattern and repeats it 
traversing the keyboard. This is a recurrent compositional device-the expansion of a musical idea by repeating the same melodic and rhythmic gesture, resulting in challenging technical passages. For instance, in the passage built on seventh chords (measures 12-16) the patterns do not conform with the beat, and the angle of the arms placed in the low register is uncomfortable. However, when sixteenth-note figurations go up, the arm position returns naturally to a conventional position. Different notes and fingers (1-2-5) are accentuated and it is necessary to feel the coordination between hands despite the displacements of the beat. (fig. 7)

Figure 7- Measures 12-16

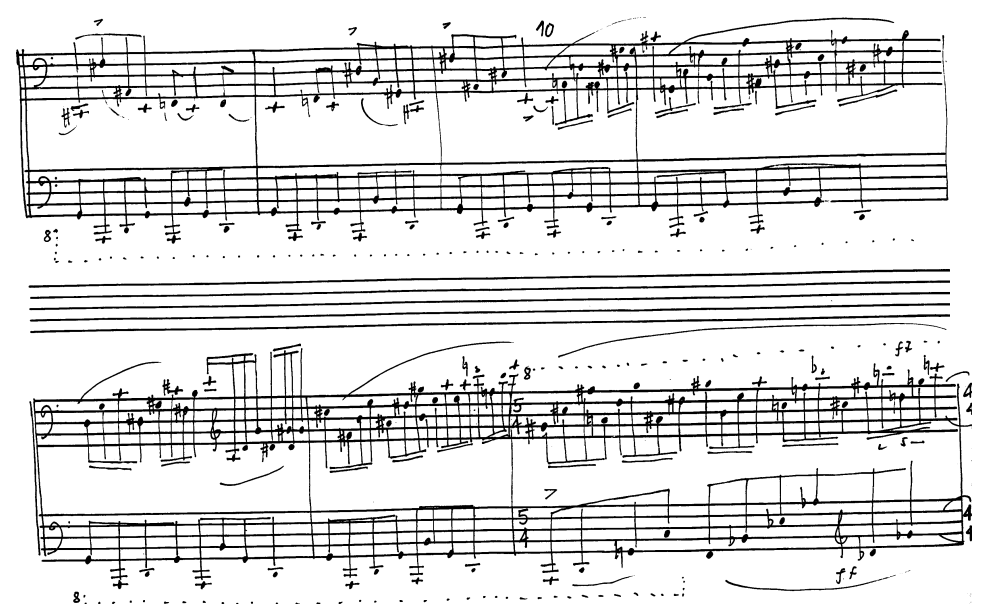

Another complex passage appears in measures 24-29, built on the Delta chord, but musical elements are different: texture, rhythm, melodic contour, tempo, character.

The combination of the hands having different melodic patterns in conjunction with the polyphonic writing makes the passage difficult from the standpoint of the sound. Usually, contrary and parallel motions with the same rhythmic figure prevail, but in this passage the elaboration of texture demands a new approach of tone production. The two layers of sound in pianissimo require contrasting sound colors and independent movements in both hands. (fig. 8) 
Figure 8- Measures 24-29

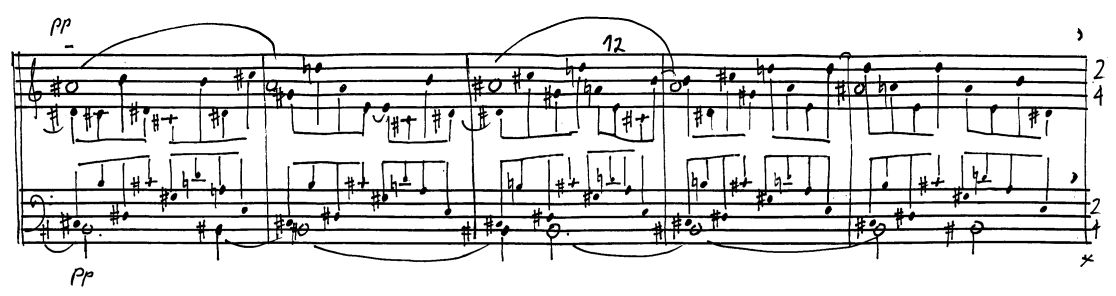

Another recurrent technical issue is to find the appropriate gesture to play passages that contain a sequence of the same melodic and rhythmic figure, imparting an appropriate musical inflection and sound approach to the passage. For example, in measures 46-50, there are two contrasting sequences in both hands, the patterns presented in contrary motion in 4 against 5 . It is important to feel the rhythmic pulse in the right hand and allow the left hand to flow naturally. The right hand gets farther apart from the left hand and traverses a large section of the keyboard whereas the left hand works in a smaller framework of the keyboard. Therefore, sequences and repetitions are the cause of technical difficulties and generate muscular tension because the composer takes a long time to introduce new material. Nevertheless, repetitions have a strong musical significance. They create resonance and build up sounds, timbres, and overtones.

The third movement (19 measures) does not have its structure established by the letters of the Greek alphabet; however, it is clearly written in ABA' form. The entire movement is basically built on arpeggiated seventh chords. Therefore, the musical tension is generated by the continuity of harmonic progressions which do not resolve, but create a feeling of suspension until the last measure. In part A (measures 1-7), the composer returns to the raw material used in the first movement, arpeggios in parallel and contrary motion. However, in the Lento section, the melody receives a new treatment in sound, character, articulation and dynamics. The ondulating nature of the melody makes the second Open Clusters NGC 2925 (Aglomerado Aberto NGC 2925) contrasting in emotion. Also, the use of triplets and quintuplets has an expressive function within the phrase; they expand and contract the phrases through various meters: $4 / 4,3 / 2$, and $5 / 4$. Part $B$ (measures 8-12), is one of the most gorgeous moments in the whole composition due to the extreme shifts of register in the melody and the tension generated by 
the chords in the left hand. Here, the best musical approach to the passage is to keep a smooth touch and to shape the phrase even with sudden contrasts of dynamics. Slow but precise attack of the keys will produce soft sounds and project the dynamics adequately. (fig. 9)

Figure 9- Measures 7-9

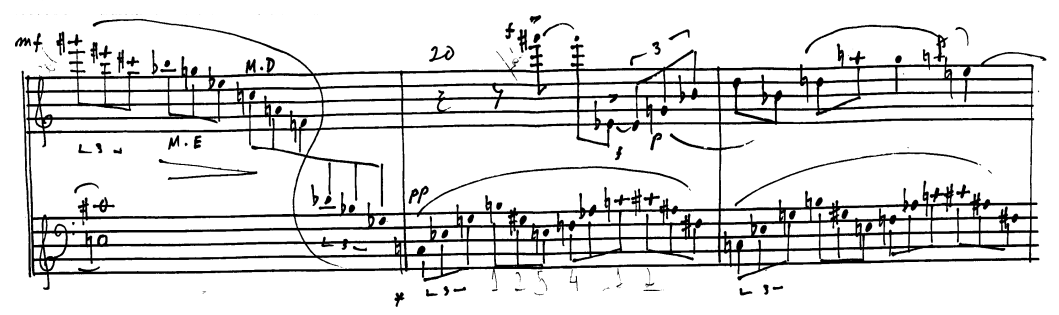

Part $A^{\prime}$ is the mirror image of the beginning. The direction of the opening arpeggios is inverted, and the quintuplets appear now in the left hand. The closing measures leave a feeling of suspension due to the juxtaposition of diminished seventh chords.

The fourth movement, Constellation of Carina (Constelação de Carina), is subtitled Waltz in Lights (Valsa em Luzes). According to the waltz genre adopted by the composer, the last movement is totally composed in 3/4, and uses various changes of metronome markings in distinctive letters. In opposition to the previous movements, now regular pulse and proportional duration of rhythmic values are the main elements in the organization of the rhythm. Larger in dimension (297 measures), the development of musical ideas is based again on the chords Alpha, Chi, Epsilon (2), Iota, Tau, Phi, Eta, Rho, Theta, Beta, and Nu. In each letter Prado develops totally new musical ideas, introducing diverse expressive devices; however, as opposed to the second movement, the composer does not retake material from various sections. On the contrary-within long sections and phrases occur sparkling changes of melodic and rhythmic material. This results in modifications in the approach to the instrument as well as technical patterns.

Tempo markings indicate that the last movement, Jubilante, Com muita flexibilidade, is markedly contrasting to the other movements in terms of character. Moreover, Prado plays with sound color through the use of contrasting registers. The composer intensively explores the middle and high registers to 
depict the image suggested in the title, while in the low register the presence of chords is the predominant feature. Furthermore, the brightness of the lights is projected in the accompaniment figures such as open fifths, tremolos built on varied intervals, rhythmic repetitions, chromatic scales, and repetition of arpeggios. These elements are difficult with respect to sound control as Prado calls for an atmospheric effect of resonances and overtones. Nevertheless, there is no need for physical struggle to play the passages containing elements with secondary function within the texture. Light finger action playing in the escapement level produces the adequate sonority, conveying the real atmosphere of the fourth movement.

In Constellation of Carina one can hear how the composer uses transtonality. In the left hand there are minor and major chords but they do not occur in a harmonic progression nor are they ever resolved. One of the most remarkable issues in this movement is how the composer transforms simple rhythmic ideas into an anti-metrical figure of high complexity. For example, a passage built on eighth notes is modified through displacements of the strong beat, hemiolas, accents and/or articulation signs. And accompaniment figures in any given tempo and rhythm will be played with a melody that disturbs the regularity of the pulse, generating technical instability.

For example, measures 79-95 present a passage that demands great control of attack in both hands, as the body is "divided into two parts," each of them playing a different role at the same time. The loud chords in the right hand can disturb the execution of soft dynamics played by the left hand. However, if the performer imparts a proper character to both hands, the bass is considered a background sound, supporting a dramatic melodic element in the right hand, the musical result of the passage is achieved. The brain works in two different ways; thus the left side deals with lightness and the right side with impetus, expressiveness, and fast gestures. (fig. 10) 
Figure 10- Measures 79-95

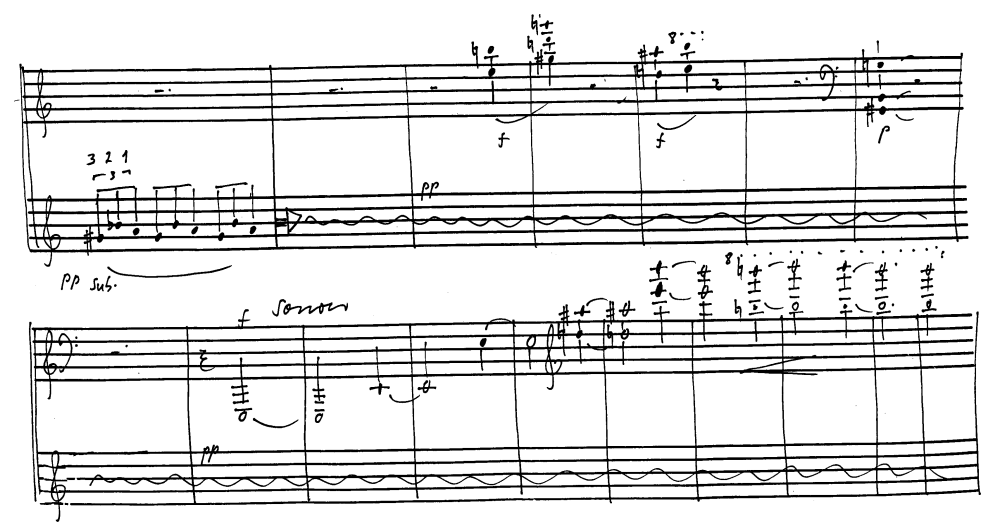

One of the most difficult passages in terms of coordination between hands occur in Rho, where groups of triplets played in both hands are modified in the bass clef through the addition of marcatos in the third eighth note of the group. It is crucial to emphasize the accents in the left hand; otherwise the passage will become ordinary. (fig. 11)

Figure 11- Measures 153-157

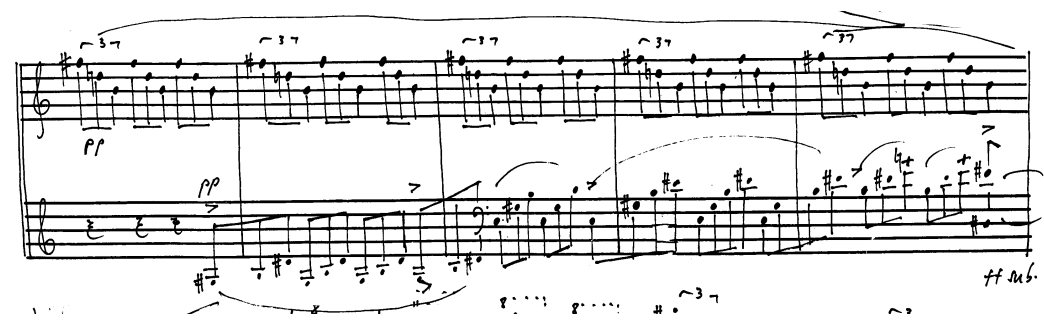

Furthermore, there is a recurrence of elements that are melodically and harmonically simple; however, the performer will have his attention focused on the rhythmic complexities and on the diversity of accents, as in Tau (measure 103), and Beta (measures 191-205). (fig. 12) 
Figure 12- Measures 103/191-205
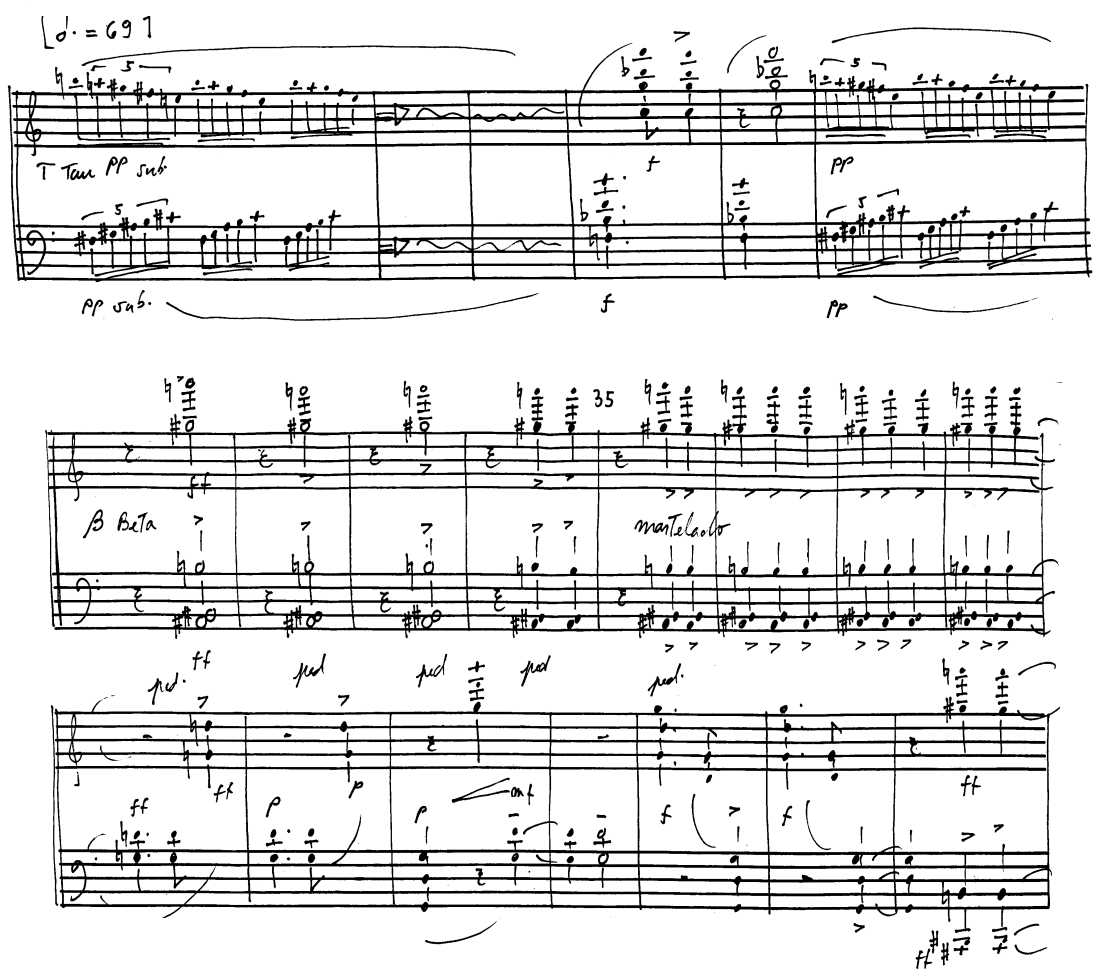

Another relevant technical point is the repetition of a specific melodic and/or rhythmic motive in a section. Usually, it is an accompaniment figure, rhythmic patterns in triplets and quintuplets, or repetition of arpeggios, which demands great control of finger action in diverse combinations, along with many kinds of movements-pronation, supination, rotation, lateral, and circular.

The coda is the most difficult section, surpassing all previous technical challenges; this section includes fast octaves in ff and use of the entire keyboard, reinforced by a dramatic musical gesture in the piece's closing. The previous avant-garde harmonic vocabulary dissolves with the surprising establishment of a tonal ending in A Major.

In summary, in Cartas Celestes XIV, it is the elaboration of melodies, rhythms, textures, harmonies, and timbre and how they interact musically that require a high technical level on the part of the pianist, as well as a refined sense of sound, color, and timbres. The combination of all parameters is what makes the piece difficult, especially the constant change of musical ideas, the alternations 
between moods and atmospheres, the intricate texture, sudden changes of tempo in the same movement, rhythmic complexities, multi-layers, articulation, and large range of dynamics.

Cartas Celestes XIV demands very advanced pianism on every level, absolute independence of movements, and a varied way of approaching the keyboard. Whereas in the first movement verticality predominates and in the third movement horizontal texture, both present important similarities: the same kind of sound control through a wealth of touches. Throughout the second and fourth movements the variety of thematic and rhythmic material, changes in texture, dynamics, and touches requires quick changes of muscular actions and great technical control. Furthermore, hand placement and the angle of the performer's arms play an important role in solving technical problems. In addition, dynamic balance between hands is necessary to bring out different layers within the texture, to create resonances, and to achieve the desired sound effect. From the technical standpoint, Prado's piece is transcendental and displays features such as jumps, leaps, fast tempos, large hand extensions, glissandi, passage work, and extreme use of registers and pedals. To this compendium of technical challenges the composer adds a gamut of dynamics - from ppp to fff - and all kinds of touches and articulations. The understanding of the varied organization of these materials is essential and will help the performer in two important ways: to give musical shape to the work, and to approach the technical issues with more objectivity in order to find quick and reasonable solutions to the challenges in the musical text.

As stated in an exhibition in the New York Planetarium, "galaxies and constellations are not uniformly spread through space. They commonly occur in pairs, groups, clusters, super clusters and show a range of shapes: spiral, elliptical and irregular." Therefore, Prado's profuse writing could be compared to that in its asymmetry, irregularities, and in the varied combination of all elements. Nevertheless, as his language is music, and having an imaginative mind that is free to explore various sources, the composer depicts the sky, stars, galaxies, and constellations through sound and the exploration of timbres, musical clusters, overtones, and resonances. 


\section{References}

PRADO, Almeida. Cartas Celestes XIV. Manuscript, 2001. . O Som de Almeida Prado. Série Interpretação e Música Brasileira, gravado em Agosto na Sala Cecília Meireles, 1999.

MANNIS, José Augusto. Centro de Documentação de Música Contemporânea, 41/2005, Unicamp, Brasil. http://www.unicamp.br/cdmc. 